\title{
Persistent severe acute respiratory syndrome coronavirus 2 detection after resolution of coronavirus disease 2019-associated symptoms/signs
}

Se Yoon Park ${ }^{1}$, Soon Gyu Yun ${ }^{2}$, Jeong Won Shin ${ }^{2}$, Bo Young Lee ${ }^{3}$, Hyo-Ju Son ${ }^{1}$, Seungjae Lee ${ }^{1}$, Eunjung Lee ${ }^{1}$, and Tae Hyong Kim $^{1}$

${ }^{1}$ Division of Infectious Diseases, Department of Internal Medicine, ${ }^{2}$ Department of Laboratory Medicine, ${ }^{3}$ Division of Allergy and Respiratory Diseases, Department of Internal Medicine, Soonchunhyang University Seoul Hospital, Seoul, Korea

\author{
Received: May 7, 2020 \\ Revised : May 19, 2020 \\ Accepted: May 21, 2020 \\ Correspondence to \\ Eunjung Lee, M.D. \\ Division of Infectious Diseases, \\ Department of Internal \\ Medicine, Soonchunhyang \\ University Seoul Hospital, 59 \\ Daesagwan-ro, Yongsan-gu, \\ Seoul 04401, Korea \\ Tel: +82-2-709-9034 \\ Fax: +82-2-709-9554 \\ E-mail: shegets@schmc.ac.kr \\ https://orcid.org/0000-0002- \\ 7724-8288
}

There are limited data on the duration of severe acute respiratory syndrome coronavirus 2 (SARS-CoV-2) RNA in respiratory specimens after resolution of coronavirus disease 2019 (COVID-19)-associated symptoms/signs. We determined duration of SARS-CoV-2 virus shedding in symptomatic patients after remission of symptoms. We investigated the duration of SARS-CoV-2 RNA detection using real-time reverse transcriptase polymerase chain reaction for SARS-CoV-2 in nasopharyngeal/oropharyngeal swabs or sputum or saliva. Six patients were included in the final analysis. The median (range) duration of SARS-CoV-2 viral detection after hospitalization was 34 days (22 to 67). After resolution of symptoms/signs, SARS-CoV-2 RNA was detected for median (range) of 26 days (9 to 48 ). Among the six patients, one had persistent detection of SARS-CoV-2 RNA until day 67 of hospitalization, which was 30 days after symptom resolution. This case represents the longest duration of SARS-CoV-2 detection, and highlights the need for long-term follow up of COVID-19 patients despite resolution of symptoms to confirm SARS$\mathrm{CoV}-2$ clearance.

Keywords: Severe acute respiratory syndrome coronavirus 2; COVID-19; Virus shedding
Since the first case of coronavirus disease 2019 (COVID-19) was reported in Wuhan, China in December 2019, the severe acute respiratory syndrome coronavirus 2 (SARSCoV-2) has infected more than three million people in 211 countries. By the end of April 2020, more than 208,000 people had died from COVID-19 [1]. Unlike other coronaviruses that have previously caused outbreaks in humans (SARS-CoV and Middle East respiratory syndrome coronavirus [MERS-CoV]), SARS-CoV-2 is reported to have a higher viral load early in the disease process [2]. The virus can also be transmitted by patients who are asymptomatic or with mild symptoms $[2,3]$.

Previous studies reported that the median duration of viral shedding is between 12-20 days, with the longest duration being 60 days [4-7]. Few studies have investigated the duration of SARS-CoV-2 detection during the patients' recovery phase after resolution of COVID-19-associated symptoms/signs. Therefore, we aimed to determine the duration of SARS-CoV-2 virus shedding in symptomatic patients after remission of symptoms. 
This study was conducted at the Soonchunhyang University Seoul Hospital, which is a 738-bed university-affiliated hospital with an eight-bed airborne infection isolation room (AIIR) for COVID-19 patients. We included all patients with confirmed COVID-19 admitted at the hospital from February 15 to March 26. The study was approved by the Institutional Review Board of Soonchunhyang University Seoul Hospital (approval number: 2020-04-039). The requirement for informed consent was waived due to the retrospective nature of the analysis.

COVID-19 was diagnosed by real-time reverse transcriptase polymerase chain reaction (RT-PCR) for SARSCoV-2 using a PowerChek ${ }^{\mathrm{TM}}$ 2019-nCoV Real-time PCR Kit (Kogenebiotech, Seoul, Korea) to determine virus through the identification of two genetic markers: envelope (E) gene and RNA-dependent RNA polymerase (RdRp) gene. Samples were obtained from the nasopharyngeal/oropharyngeal swab, sputum, and saliva. Demographic data collected included age, sex, and underlying illness. Clinical data included initial symptom or sign associated with COVID-19, treatment regimen, duration from admission to resolution of symptoms and signs, and time taken to resolution of lung findings on chest $\mathrm{X}$-ray. Time from resolution of COVID-19-associated symptoms/signs to last positive result before consecutive negative results was also noted.

Of the seven patients admitted to the hospital, one was excluded from the analysis for being transferred to the hospital on day 6 . Four patients had pauci-symptoms of general weakness, anosmia/taste disorder, sore throat, and headache. Two patients were diagnosed with pneumonia on chest computed tomography. The remaining two patients had productive cough and were diagnosed with SARS-CoV-2 pneumonia (Table 1). Detailed laboratory test results on hospital admission are shown in Supplementary Table 1.

The median (range) time from onset of symptom/sign to admission was 5 days (2 to 11). The median (range) duration of symptom/sign in six patients and lung lesions on chest radiography in four patients after hospitalization was 5 days ( 4 to 38 ) and 18 (12 to 36 ), respectively. The total duration of SARS-CoV-2 viral shedding after hospitalization was median (range) 34 days (22 to 67). SARSCoV-2 was detected after median 26 days (9 to 48) after resolution of symptoms/signs (Table 1 and Fig. 1).

Table 1. Clinical characteristics of coronavirus disease 2019 patients

\begin{tabular}{|c|c|c|c|c|c|c|}
\hline Characteristic & Patient 1 & Patient 2 & Patient 3 & Patient 4 & Patient 5 & Patient 6 \\
\hline Age/Sex & $21 / F$ & $57 / \mathrm{F}$ & $30 / \mathrm{F}$ & $42 / \mathrm{M}$ & $48 / \mathrm{F}$ & 49/M \\
\hline Underlying diseases & None & $\begin{array}{c}\text { Schizophrenia, } \\
\text { HTN }\end{array}$ & None & RA & $\begin{array}{l}\text { Breast } \\
\text { cancer }\end{array}$ & HTN \\
\hline Symptoms/signs & $\begin{array}{l}\text { Cough, } \\
\text { sputum, } \\
\text { sore throat }\end{array}$ & $\begin{array}{l}\text { Fever, cough, } \\
\text { sputum }\end{array}$ & $\begin{array}{c}\text { General } \\
\text { weakness, } \\
\text { Febrile sense }\end{array}$ & $\begin{array}{l}\text { Anosmia, } \\
\text { taste disorder }\end{array}$ & $\begin{array}{l}\text { Sore } \\
\text { throat }\end{array}$ & Headache \\
\hline Chest image & Pneumonia & Pneumonia & WNL & Pneumonia & WNL & Pneumonia \\
\hline Treatment & HCQ & $\begin{array}{c}\text { Lopinavir/ } \\
\text { Ritonavir, HCQ }\end{array}$ & HCQ & HCQ & None & HCQ \\
\hline $\begin{array}{l}\text { Time to resolution of symptom } \\
\text { /sign after hospitalization, day }\end{array}$ & 29 & 38 & 5 & 5 & 5 & 4 \\
\hline $\begin{array}{l}\text { Time to resolution of lung lesion } \\
\text { after hospitalization, day }\end{array}$ & 17 & 36 & NA & 12 & NA & 18 \\
\hline $\begin{array}{l}\text { Duration of SARS-CoV-2 virus } \\
\text { detection after hospitalization }\end{array}$ & 37 & 67 & 29 & 30 & 52 & 22 \\
\hline $\begin{array}{l}\text { Duration of SARS-CoV-2 virus } \\
\text { detection after symptom/sign } \\
\text { resolution }\end{array}$ & 9 & 30 & 25 & 26 & 48 & 19 \\
\hline
\end{tabular}

HTN, hypertension; RA, rheumatoid arthritis, HCQ, hydroxychloroquine; WNL, within normal limit; NA, not available; SARS-CoV-2, severe acute respiratory syndrome coronavirus 2. 

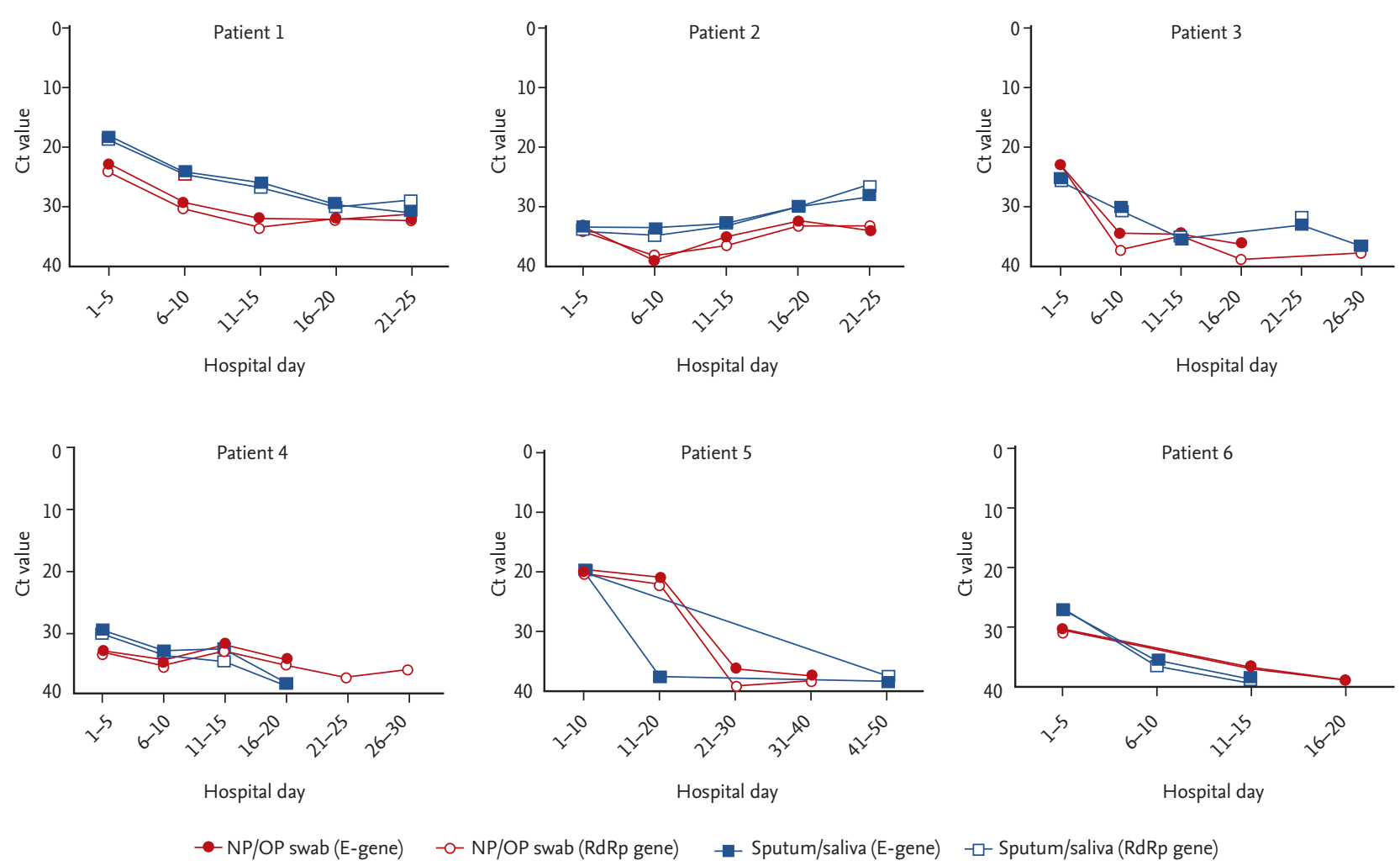

Figure 1. Dynamics of the nasopharyngeal (NP) and oropharyngeal (OP) swab and sputum or saliva severe acute respiratory syndrome coronavirus 2 detection and cycle threshold (Ct) values according to hospital days. RdRp, RNA-dependent RNA polymerase.

Patients 1 and 2 were still hospitalized on May 4, 2020 while the others had been discharged. However, patient 5 was re-admitted on April 25, 202021 days after discharge due to positive result on nasopharyngeal and oropharyngeal swab testing (cycle threshold [Ct] value for E gene 32.68; and RdRp gene 33.31). Patient 5 was on scheduled adjuvant chemotherapy after breast cancer surgery. Therefore, we repeated SARS-CoV-2 PCR test every 2 to 3 days prior to chemotherapy. She was re-discharged 2 days later after consecutive negative result on follow-up tests. Patient 2 continued shedding SARSCoV-2 in hospital day (HD) 67, with high viral titer in the sputum (E gene Ct 28.23; RdRp gene Ct 26.89). The patient had underlying comorbidities (schizophrenia and hypertension), and required 5 days of oxygen supplementation. She received 10 days of lopinavir/ritonovir, followed by hydroxychloroquine, but viral shedding persisted for more than 67 days (Supplementary Fig. 1).

SARS-CoV-2 shedding continued for about 4 weeks after resolution of COVID-19-associated symptoms/signs, with the longest period being 48 days. In this study, four patients with pauci-symptoms had SARS-CoV-2 detected after admission for 22 to 52 days. This finding suggests that SARS-CoV-2 shedding may continue for more than 3 weeks regardless of presence of COVID-19 symptoms. The shedding may be further prolonged as with patient 2, who to our knowledge, has the longest ongoing virus shedding among the reported COVID-19 patients.

Data from a prospective cohort study of 137 patients with COVID-19 indicated that the duration of viral detection was a median of 12 days, with a maximum of 45 days [6]. The risk factors for prolonged SARS-CoV-2 detection include older age, disease severity, lower lymphocyte, eosinophil, and CD8+ T cells count, and higher interleukin 6 (IL-6) and IL-10 levels [6]. Patient 2, who had the longest duration of viral detection, was older $(57$ years) and had the lowest lymphocyte count $\left(778 / \mathrm{mm}^{3}\right)$ on admission. In this present study, we also found that the virus can be detected for weeks after the resolution 
of clinical symptoms in younger patients who were mildly symptomatic and without lymphopenia (patients $3,4,5$, and 6).

In the present study, patient 5 was discharged after negative PCR test results. The patient was re-hospitalized after testing positive three weeks of discharge. Case study from China report similar patterns [8]. The genetic material of dead viral particles remaining within epithelial cells can be detected as epithelial cells are desquamated. Respiratory epithelial cells have a long halflife of up to months to years [9]. Therefore, during the recovery phase, it is likely that the PCR could show the fluctuation. Moreover, low nucleic acid content can reduce the reliability of the test (e.g., increasing results of false positives). To understand the best approaches and solutions (e.g., the necessity of re-isolation or self-isolation) to the fluctuations during their recoveries, further investigations are needed to review the display of the patients' symptoms and the presence of the live virus.

This study had some limitations. First, we included only respiratory samples from only six patients. Further studies, with a larger sample size, are needed to gather further information regarding viral shedding using various types of samples. Second, viral culture, which is the gold standard for viral detection with infectivity, was not undertaken. It is possible that detection of SARS-CoV-2 with a comparatively lower viral titer could involve dead viral particles. It is necessary to confirm the presence of live virus for cases with trends similar to that patient 2 showed, considering that the patient showed increasing viral loads.

In conclusion, we found that SARS-CoV-2 virus shedding can persist for more than three weeks after resolution of COVID-19-associated symptoms/signs. Due to prolonged viral shedding after resolution of COVID-19-associated symptoms/signs and limited number of AIIRs, the securing and distribution of AIIRs at the national level should be decided considering these characteristics.

\section{Conflict of interest}

No potential conflict of interest relevant to this article was reported.

\section{Acknowledgments}

This research was supported by the Soonchunhyang University Research Fund.

\section{REFERENCES}

1. World Health Organization. Coronavirus disease 2019 (COVID-19) situation reports [Internet]. Geneva (CH): World Health Organization, c2020 [cited 2020 Jun 4]. Available from: http://www.who.int/emergencies/diseases/ novel-coronavirus-2019/situation-reports.

2. Zou L, Ruan F, Huang M, et al. SARS-CoV-2 viral load in upper respiratory specimens of infected patients. N Engl J Med 2020;382:1177-1179.

3. Li C, Ji F, Wang L, et al. Asymptomatic and human-to-human transmission of SARS-CoV-2 in a 2-family cluster, Xuzhou, China. Emerg Infect Dis 2020 Mar 31 [Epub]. https://doi.org/10.3201/eid2607.200718.

4. Zhou F, Yu T, Du R, et al. Clinical course and risk factors for mortality of adult inpatients with COVID-19 in Wuhan, China: a retrospective cohort study. Lancet 2020;395:1054-1062.

5. Qian GQ, Chen XQ, Lv DF, et al. Duration of SARS-CoV-2 viral shedding during COVID-19 infection. Infect Dis (Lond) 2020;52:511-512.

6. Lin A, He ZB, Zhang S, Zhang JG, Zhang X, Yan WH. Early risk factors for the duration of SARS-CoV-2 viral positivity in COVID-19 patients. Clin Infect Dis 2020 Apr 27 [Epub]. https://doi.org/10.1093/cid/ciaa49o.

7. Li J, Zhang L, Liu B, Song D. Case report: viral shedding for 60 days in a woman with novel coronavirus disease (COVID-19). Am J Trop Med Hyg 2020;102:1210-1213.

8. Chen D, Xu W, Lei Z, et al. Recurrence of positive SARSCoV-2 RNA in COVID-19: a case report. Int J Infect Dis 2020;93:297-299.

9. Rawlins EL, Hogan BL. Ciliated epithelial cell lifespan in the mouse trachea and lung. Am J Physiol Lung Cell Mol Physiol 2008;295:L231-L234. 
Supplementary Table 1. Laboratory test results of coronavirus disease 2019 patients at hospital admission

\begin{tabular}{|c|c|c|c|c|c|c|}
\hline Variable & Patient 1 & Patient 2 & Patient 3 & Patient 4 & Patient 5 & Patient 6 \\
\hline White blood cell count, / $/ \mathrm{L}$ & 6,100 & 2,600 & 10,000 & 4,700 & 6,600 & 4,400 \\
\hline Neutrophil count, $/ \mu \mathrm{L}$ & 4,091 & 1,286 & 5,109 & 1,750 & 1,320 & 2,162 \\
\hline Lymphocyte count, $/ \mu \mathrm{L}$ & 1,388 & 778 & 4,111 & 2,474 & 1,122 & 1,572 \\
\hline Eosinophil count, $/ \mu \mathrm{L}$ & 57 & 61 & 87 & 60 & 66 & 31 \\
\hline Platelet count, $/ \mu \mathrm{L}$ & 232,000 & 266,000 & 244,000 & 236,000 & 168,000 & 150,000 \\
\hline Creatinine, $\mathrm{mg} / \mathrm{dL}$ & 0.67 & 0.51 & 0.68 & 0.88 & 0.55 & 0.01 \\
\hline Albumin, g/dL & $4 \cdot 4$ & 3.8 & 4.8 & 4.8 & $4 \cdot 5$ & 4.7 \\
\hline Alanine aminotransferase, U/L & 22 & 40 & 20 & 19 & 34 & 27 \\
\hline Aspartate aminotransferase, U/L & 13 & 28 & 14 & 19 & 54 & 22 \\
\hline Prothrombin times, sec & 11.1 & 11 & 10.6 & 11.9 & 12 & 10.8 \\
\hline $\mathrm{CK}, \mathrm{U} / \mathrm{L}$ & 46 & 257 & 48 & 82 & 21 & 66 \\
\hline $\mathrm{CRP}, \mathrm{mg} / \mathrm{dL}$ & 1.29 & $5 \cdot 34$ & 0.01 & 0.08 & 1.27 & 1.48 \\
\hline Procalcitonin, ng/mL & 0.06 & 0.07 & 0.03 & 0.03 & NA & NA \\
\hline
\end{tabular}

CK, creatine kinase; CRP, C-reactive protein; NA, not available. 


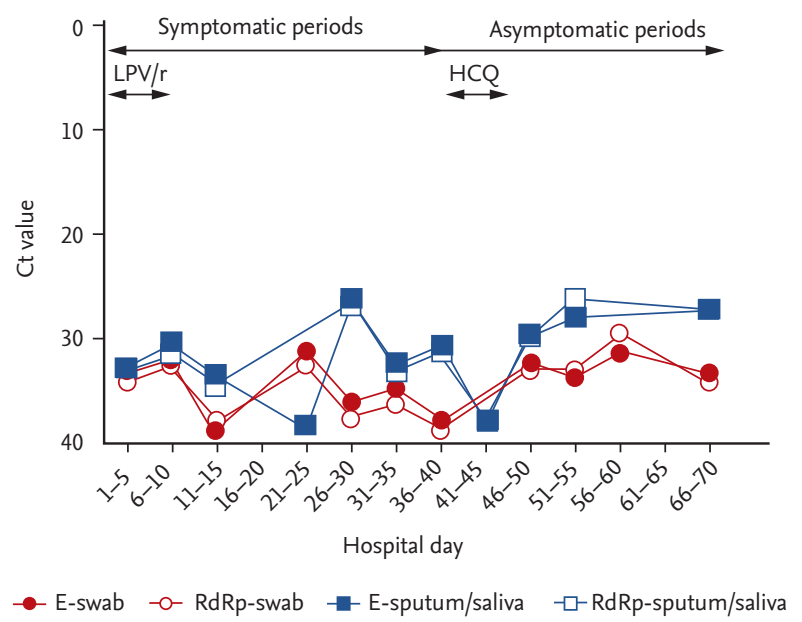

Supplemental Figure 1. Detailed dynamics of severe acute respiratory syndrome coronavirus 2 virus detection in the upper and lower respiratory tract specimens of patient 2 according to hospital days. LPV/r, lopinavir/ritonavir; HCQ, hydroxychloroquine; RdRp, RNA-dependent RNA polymerase; $\mathrm{Ct}$, cycle threshold. 